\section{A Case of Haemophilia with Marfan's Syndrome}

Brit. med. F., 1964, 1, 102-103

The case of a male haemophiliac with an abnormal large chromosome was recently reported (Elves and Israëls, 1962). This patient was eunochoid, of normal intelligence, and showed arachnodactyly in both hands and feet, a high arched palate, slight kyphosis, and a mild degree of hypospadias. Sex chromatin in the buccal mucosa was negative. An abnormal large chromosome was, however, found, and this was thought to be an abnormal $\mathrm{X}$. We now report a case which is similar in some respects.

\section{CASE REPORT}

The patient, a known haemophiliac, was admitted to Queen Mary's Hospital for Children, Carshalton, on 28 March 1962, at the age of 15 years, primarily for education. When he was 1 year old he had developed a swelling of the right knee which was the earliest recorded manifestation of his haemophilia. He had since been admitted several times to various hospitals with epistaxis, haematuria, haemarthrosis, and other haemorrhagic episodes. The diagnosis has been confirmed by laboratory tests: thromboplastin generation tests performed at St. Bartholomew's Hospital, Rochester, and Queen Mary's Hospital for Children, Carshalton, showed gross clotting defect in the patient's plasma: The whole-blood clottingtime was greatly prolonged and the one-stage prothrombin time slightly prolonged. Several antihaemophilic globulin assays have been done at the Hammersmith Hospital and the pretransfusion values were between 0 and $2 \%$ of the normal level.

There was no family history of haemophilia. Both his mother and his sister displayed features of Marfan's syndrome. In addition his mother had had diabetes mellitus since the age of 28 and also suffered from hypothyroidism. His sister, who had a diaphragmatic hernia, genu valgum, depressed sternum, and scoliosis, died at the age of 10 years from a ruptured berry aneurysm of the circle of Willis.

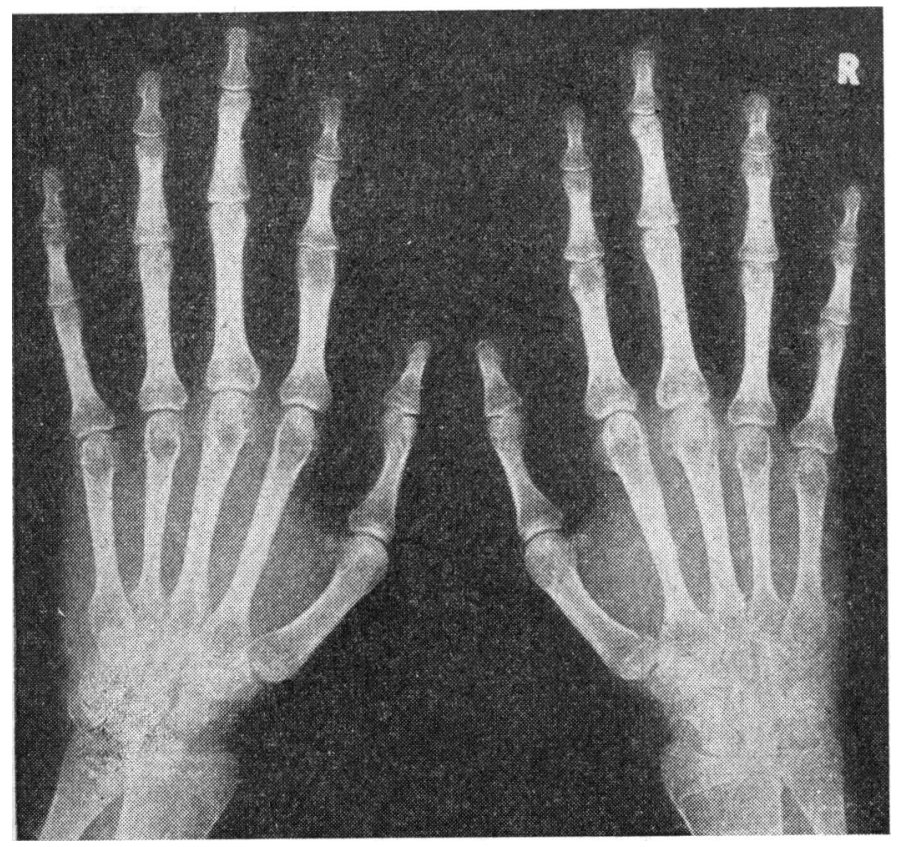

FIG. 1.-Radiograph of hands.
On physical examination the patient was $6 \mathrm{ft}$. $(183 \mathrm{~cm}$.) tall with arachnodactyly, high arched palate, myopia, but no lens dislocation. He had kyphoscoliosis, a slight pigeon-chest deformity, some degree of gynaecomastia, obesity with striae over hips, abdomen, and chest wall, and female hair distribution. His penis was rather small but his testes were in the scrotum and appeared to be normal in size. He showed joint manifestations due to haemophilia. His fingers were very long (Fig. 1) and $x$-ray examination of his hands gave a metacarpal index of 9.0, which is consistent with arachnodactyly. $X$-ray examination of the chest showed gut in the right hemithorax.

Plasma and urinary steroid studies were carried out at Hammersmith Hospital in 1960. These showed no abnormality. His chromosomes were then investigated. The total number of cells counted was 50: of these, 47 cells showed 46 chromosomes, 1 cell had 47 (i.e., $46+$ fragment), 1 had 45 (Y chromosome missing), and 1 cell had 44 chromosomes. Five cells were analysed-all containing 46 chromosomes. $\mathrm{He}$ is reported as having a normal male karyotype. His buccal smear was negative with regard to sex chromatin, and no drumsticks were seen in a count of 300 neutrophil polymorphonuclear leucocytes.

About six months after admission an extensive haemorrhage occurred into the tissues of the upper and lower respiratory tract. Sudden respiratory failure occurred and he died on 15 September 1962.

Post-mortem Examination.-Extravasated blood was found in the respiratory tract and lungs, in the tissues of mouth and neck, and in the abdomen. A defect $5 \mathrm{~cm}$. in diameter was situated on the right side of the diaphragm ; the stomach, part of the small intestine, and the transverse colon had passed through it into the thoracic cavity. The spleen and liver were slightly enlarged and congested. The epicardium showed some bruising typical of cardiac massage. The heart and the great vessels appeared normal. There was no abnormality in the endocrine, genito-urinary, and central nervous systems. The meninges showed a few areas of subarachnoid haemorrhage.

Histology.-Tissues examined after paraffin embedding comprised the heart, lungs, spleen, liver, pancreas, kidneys, oesophagus, adrenals, pituitary, thyroid, testis, breast, skeletal muscle, bonemarrow, and several levels of brain and spinal cord. The usual histological stains were used. The lungs and thyroid showed extravasated blood. The kidney also showed haemorrhages. The epithelium of some of the convoluted tubules showed cloudy swelling and partial necrosis. The cells of the zona reticulosa in the adrenal cortex were necrotic in a few areas. The central nervous system presented some unevenness of neuronal staining and central chromatolysis. Degenerative, possibly terminal, change was present in some of the Purkinje cells. The testes were normal in size. The differentiation of the tubular epithelium was proceeding normally

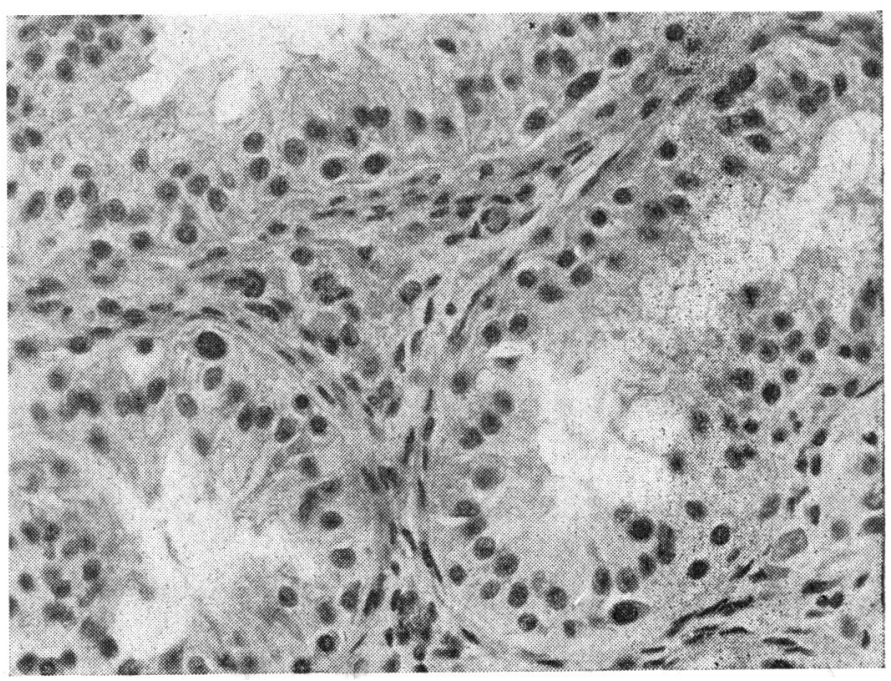

FIG. 2.-Photomicrograph of testis showing azoospermia. $(\times 255$. 
up to the primary spermatocyte level. However, rather few secondary spermatocytes and very scanty spermatids were seen. No spermatozoa were present in any of the tubules. Leydig cells were present in normal numbers (Figs. 2 and 3). In the mammary gland, which was formed mainly by hypocellular collagen fibres, there were numerous ducts; some were greatly dilated. The lining epithelium of the ducts varied, being one layer deep in some areas and stratified in others. The cells of the unicellular layer were flattened and endothelium-like, cuboidal or columnar (Fig. 4). In the pituitary

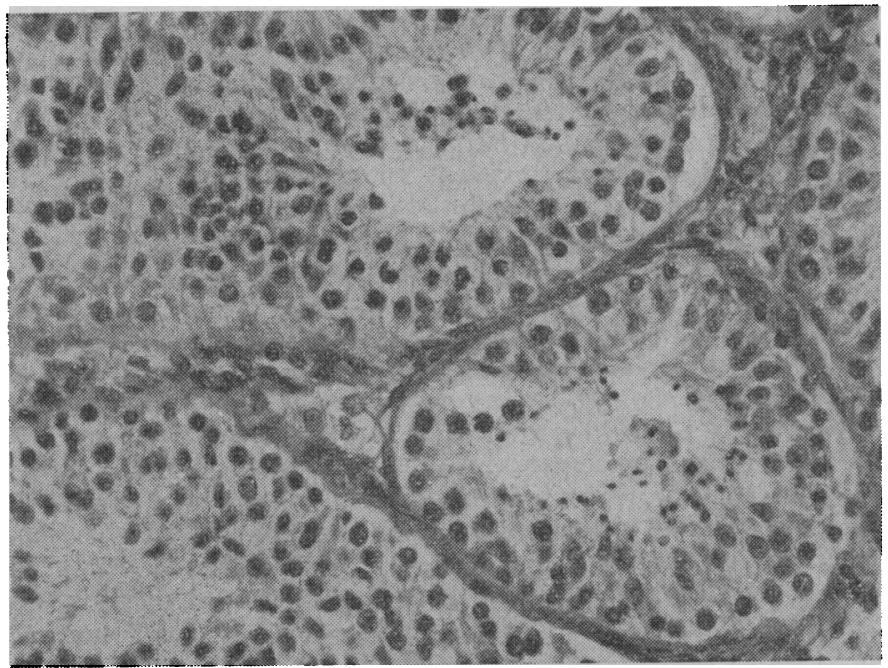

FIG. 3.-Photomicrograph of normal testis of a boy about the same age. $(\times 255$.

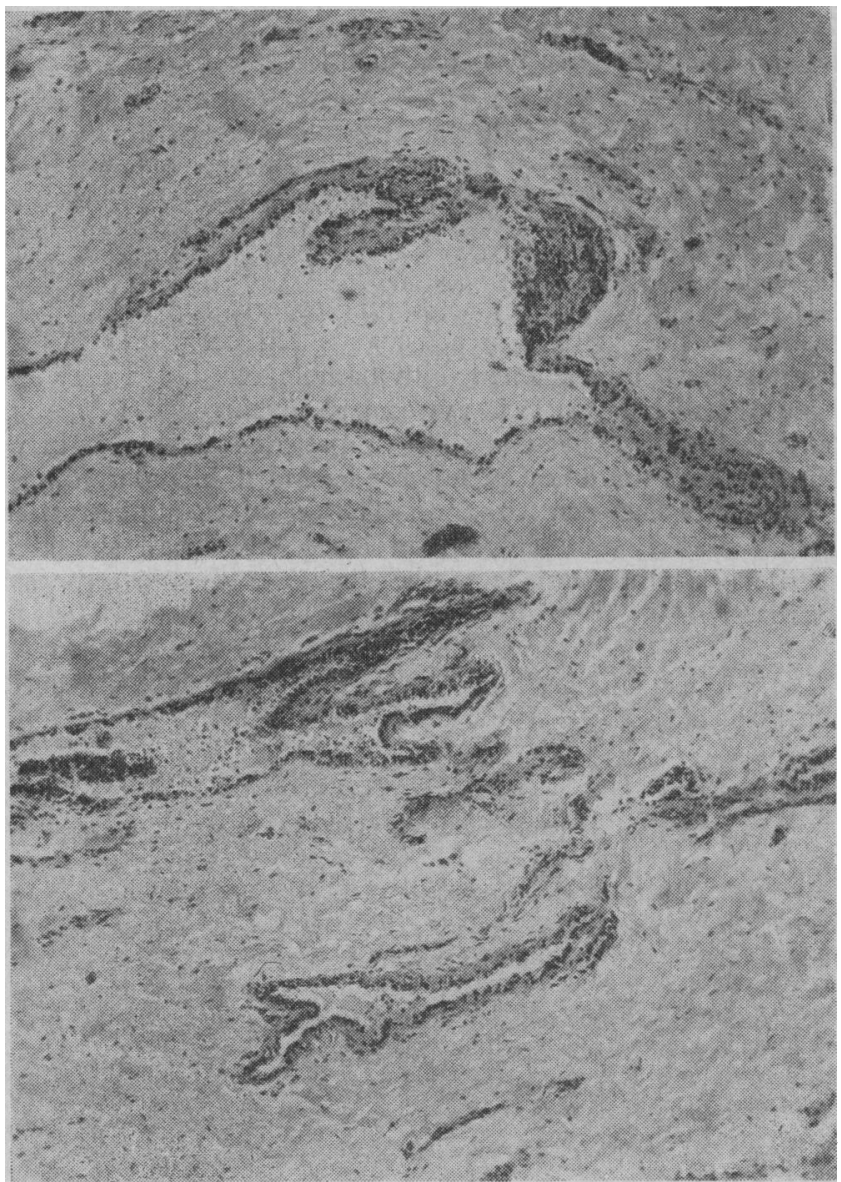

FIG. 4.-Mammary gland containing dilated ducts. $(\times 90$.) body several of the main cell types showed hyperplasia, though there was thought to be no appearance of specific changes.

\section{Discussion}

We consider our case to be one of Marfan's syndrome qn account of the clinical findings of arachnodactyly, a high arched palate, wide pelvis and narrow shoulders, kyphoscoliosis, and slight pigeon-chest deformity. This view is further supported by the family history, together with the generally accepted opinion that Marfan's syndrome is inherited as a single Mendelian dominant autosomal factor with pleiotropism.

Certain of the clinical features were seen also in the case described by Elves and Israëls (1962), though they do not mention the diagnosis of Marfan's syndrome. Moreover, both their patient and ours suffered from haemophilia. Hitherto, haemophilia has not been described in association with Marfan's syndrome.

Our patient showed signs of feminization, but no abnormality was found involving the $\mathrm{X}$ or any other chromosome. The patient of Elves and Israëls was eunuchoid, apparently showing signs of sexual infantilism rather than of feminization, and had an anomaly presumably involving the $\mathrm{X}$ chromosome. It is interesting to speculate on whether our case also may have had an anomaly of the $\mathrm{X}$ chromosome, but not detectable by present methods, and to reflect that haemophilia is determined by an $\mathrm{X}$-borne gene.

Features associated with genito-urinary tract have been reported occasionally in Marfan's syndrome. These have been reviewed by Sinclair, Kitchin, and Turner (1960). Also it has been stated that there is a tendency to poor development of the secondary sexual characteristics (Fischl and Ruthberg, 1951). Reports in the literature of associated hypogonadism have not been supported by accounts of histological findings. In our case the testes were normal in size, though histological examination showed azoospermia.

The clinical findings would suggest that the features of our case might be of the same genetical aetiology as those in the case of Elves and Israëls, though it is difficult to advance this more than speculatively since there is a discrepancy between the two cases with respect to the chromosomal findings.

We wish to thank Dr. David Lawson, Queen Mary's Hospital, Carshalton; Professor J. V. Dacie, Professor M. D. Milne, and Dr. O. M. Wrong, Hammersmith Hospital ; and Dr. R. A. Moir, St. Bartholomew's Hospital, Rochester, for permission to publish an account of the patient, who had been under their care. We are also grateful to Professor L. S. Penrose and the staff of the Galton Laboratory for the chromosomal investigations; to Dr. A. G. Everson Pearse for examination of the pituitary body ; and to Dr. B. C. H. Ward for metacarpal index data.

M. ERDOHAZI, M.D.,

Registrar in Pathology, Queen Mary's Hospital for Children, Carshalton.

VALERIE CoWIE, M.D., D.P.M.;

Consultant Psychiatrist, Queen Mary's Hospital for Children, Carshalton; Assistant Director, Medical Research Council, Psychiatric Genetics Research Unit, Maudsley Hospiral, London.

S. S. Lo, M.D., D.C.H., Registrar, Queen Mary's Hospital for Children, Carshalton.

\section{REFERENCES}

Elves, M. W., and Israëls, M. C. G. (1962). Lancet, 2, 909.

Fischl, A. A., and Ruthberg, J. (1951). F. Amer. med. Ass., 146, 704. Sinclair; R. I., Kitchin, A. H., and Turner, R. W. (1960). Quart. F. Med., 29, 19. 